\title{
Empathy in Medical Students as Related to Gender, Year of Medical School and Specialty Interest
}

\author{
Duarte, M.I., Branco, M.C., Raposo, M.L., Rodrigues, P.J
}

\begin{abstract}
The existence of empathy in the physician-patient clinical relationship enables a positive impact on interactions and is an essential aspect of care quality associated with patient satisfaction and adherence to treatment. The purpose of this research is to determine the students' empathy level over the course and their different specialty interests. This cross-sectional study involved a sample of 208 undergraduate medical students who responded to the Jefferson Scale of Physician Empathy Student Portuguese Version (JSPE-spv). The results show that female students outscore men on the empathy level which increases throughout the six year course. The people-oriented specialty group also showed higher scores.
\end{abstract}

Keywords: JSPE-spv, relationships, specialties.

\section{Introduction}

Empathy is an important factor of interpersonal relationships and improves understanding and communication between individuals. It has a positive impact on physician-patient relationship and their interactions. It is an essential aspect in quality of care, patient satisfaction and adherence to treatment, and may even contribute to an improvement in clinical outcomes (Pollak et al., 2007).

According to Chen et al, (2007) this concept consists of physician's ability to recognize and cognitively understand the patients' perspectives and experiences and the ability to convey such understanding back to the patient. In literature, some studies show the empathy average scores decline during university medical education (Chen et al., 2007; Hojat et al., 2009). However, more recent studies have provided different results; Magalhães et al. (2011) concluded that senior year students have a higher score of empathy than a freshman. Cross-sectional studies in Japan and Korean found the highest values measures of empathy in senior students (Kataoka et al., 2009; Roh et al., 2010).

University of Beira Interior (UBI)

Avenida Infante D. Henrique, 6200-506 Covilhã

Portugal

Corresponding author

Marta Isabel Duarte

University of Beira Interior (UBI)

Avenida Infante D. Henrique, 6200-506 Covilhã - Portugal +351275329007

E-mail address: martad@fcsaude.ubi.pt
In all the analysed studies, women's empathy levels outscore those of men (Kataoka et al., 2009, Roh et al., 2010; Quince et al., 2011; Magalhães et al., 2011).

Several studies found significantly different JSPE scores among physicians in different specialties (Hojat et al., 2009; Chen, 2007).

Hojat et al, (2005) divides the specialties into four groups: a) procedure-oriented specialties (e.g. radiology, pathology); b) technologyoriented specialties (e.g. ophthalmology, neurosurgery, orthopedic surgery); c) nonprimary care specialties (e.g. cardiology, gastroenterology, psychiatry); d) peopleoriented specialties (e.g. family medicine, general internal medicine, general pediatrics).

By using a sample of medical students of the Beira Interior University's School of Health Sciences, this study intends to observe the students' empathy level on the first, third and sixth years. It also intends to ascertain the different empathy levels according to their different specialty interests.

\section{Methodology}

Participants

Medical students of the first, third and sixth years were voluntarily involved. The students were assured about the confidentiality of their answers.

\section{Means}

The measurement of empathy in medical students was based on the Jefferson Scale of 
Physician Empathy - Student Portuguese Version (JSPE-spv) which includes 20 items in a 7 point Likert-type scale (1 - strongly disagree, 7 - strongly agree).

The translation and adaptation of JSPE-spv was proposed in a Portuguese work by Magalhães et al, (2010). There were 10 questions where responses were scored accordingly, from 1 (strongly agree) to 7 (strongly disagree).

\section{Procedures and Statistical Analysis}

An anonymous and confidential web survey was used to collect data. To analyze the relation between empathy levels and specialty interests, the survey included one item asking the students about the specialty they would like to pursue in the future. The data was then submitted to a varied and descriptive statistical analysis according to the statistical package SPSS - version 19.

First it consisted in calculating the JSPE-spv total score, the average standard deviation and the internal consistency of the scale (Cronbach's alpha coefficient).

Then the t-test was applied to analyse empathy levels of men and women from the first, third and sixth years. The ANOVA Test was used to identify the general averages of different specialty groups.
Finally a t-test and Anova were used to identify the total scores of the different groups (gender and specialties, gender and year in medical school, specialties and year in medical school). The averages allowed identification of the specialty and year where women and men obtained the highest scores, as well as the students' favoured specialty on the first, third and the sixth years.

\section{Results}

In the final sample of 208 students, there were 148 females $(71,2 \%)$ and 60 males $(28,8 \%)$, with an average age of 21,38 years $(S D=2.77)$. Of the respondents, 75 were in the first year, 64 in the third year and 67 in the sixth year.

When comparing genders, (Table 1) women scored significantly higher on empathy than men $(\mathrm{t}(206)=4,348, \mathrm{p}=0,000)$. The average score among the student groups showed an increase across the years of study, with an average empathy score of 112.85 in the first year, 113.74 in the third year and to 116.78 in the sixth. The Anova test however, showed no statistically relevant differences $\left(F_{(2)}=2,505\right.$, $p=0,084)$. No relevant differences were found among students with different specialty interests. Considering the average empathy level, students who indicated interest in people-oriented specialties reached higher scores than those who had other preferences. However, this was not statistically significant.

Table 1: Average scores and group differences

\begin{tabular}{lcccc}
\hline \multicolumn{1}{c}{ Groups } & N & A & SD & p \\
\hline Gender & 148 & 116,41 & 10,47 & $<0,001(\mathrm{a})$ \\
1. Female & 60 & 109,45 & 10,42 & \\
2. Male & & & & \\
\hline Year in Medical School & 75 & 112,85 & 10,46 & NS(b) \\
1. $1^{\text {st }}$ year & 66 & 113,74 & 11,57 & \\
2. $3^{\text {rd }}$ year & 67 & 116,78 & 10,43 & \\
3. $6^{\text {th }}$ year & & & & \\
\hline Specialty Interest & 10 & 113,20 & 10,8 & \\
1. Procedure Oriented & 37 & 114,54 & 9,77 & NS(c) \\
2. Technology Oriented & 84 & 113,81 & 11,40 & \\
3. Non-Primary Care & 58 & 115,66 & 11,30 & \\
4. People Oriented & 19 & & & \\
5. No Response & & & \\
\hline
\end{tabular}
(a) $\mathrm{t}_{(206)}=4,348, \mathrm{p}=0,000$
(b) $F(2)=2,505, p=0,084$
(c) $\mathrm{F}_{(46)}=0,655, \mathrm{p}=0,952$ 
The t-test and Anova Test were used to observe the relation between gender and specialty, gender and year in medical school and specialties. The results (Table 2) only highlighted relevant differences between gender, technology-oriented and non-primary- care specialties. By looking at average results one may see that women have higher scores in technology-oriented specialties and men in procedure-oriented specialties. Students in later stages of training revealed higher scores than the first year students.

Table 2: Comparative analysis of groups

\begin{tabular}{|c|c|c|c|c|c|}
\hline Groups & $\mathbf{N}$ & A & SD & & \\
\hline Gender*Specialties & & & & \multirow{3}{*}{$t_{(8)}=-0,124$} & \multirow{3}{*}{ NS } \\
\hline Women*procedure oriented & 6 & 112,83 & 9,93 & & \\
\hline Men*procedure oriented & 4 & 113,75 & 13,60 & & \\
\hline Women`technology oriented & 21 & 118,19 & 7,20 & \multirow{2}{*}{$t_{(35)}=2,849$} & \multirow{2}{*}{$\mathrm{p}=0,007$} \\
\hline Men* technology oriented & 16 & 109,75 & 10,81 & & \\
\hline Women*non-primary care & 59 & 116,17 & 11,33 & \multirow{2}{*}{$t_{(82)}=3,057$} & \multirow{2}{*}{$\mathrm{p}=0,003$} \\
\hline Men* non-primary care & 25 & 108,24 & 9,66 & & \\
\hline Women*people oriented & 50 & 116,30 & 10,73 & \multirow{2}{*}{$\mathrm{t}_{(56)}=1,088$} & \multirow{2}{*}{ NS } \\
\hline Men* people oriented & 8 & 111,63 & 14,55 & & \\
\hline \multicolumn{6}{|c|}{ Gender ${ }^{*}$ Year in Medical School } \\
\hline Women $1^{\text {st }}$ year & 50 & 115,04 & 9,86 & \multirow[b]{2}{*}{$t_{(73)}=2,662$} & \multirow[b]{2}{*}{$p=0,010$} \\
\hline Men $1^{\text {st }}$ year & 25 & 108,48 & 10,44 & & \\
\hline Women*3 year & 46 & 116,07 & 10,76 & \multirow[b]{2}{*}{$t_{(64)}=2,580$} & \multirow[b]{2}{*}{$\mathrm{p}=0,012$} \\
\hline Men $3^{\text {ra }}$ year & 20 & 108,40 & 11,84 & & \\
\hline Women $6^{\text {th }}$ year & 52 & 118,02 & 10,74 & \multirow{2}{*}{$\mathrm{t}_{(65)}=1,849$} & \multirow{2}{*}{ NS } \\
\hline $\operatorname{Men}^{*} 6^{\text {th }}$ year & 15 & 112,47 & 8,20 & & \\
\hline \multicolumn{6}{|c|}{ Specialties* Year in Medical School } \\
\hline Procedure oriented ${ }^{*} 1^{\text {st }}$ year & 2 & 110,50 & 4,95 & \multirow{3}{*}{$F_{(2)}=0,072$} & \multirow{3}{*}{ NS } \\
\hline Procedure oriented ${ }^{*} 3^{\text {ra }}$ year & 3 & 114,67 & 17,9 & & \\
\hline Procedure oriented ${ }^{*} 6^{\text {th }}$ year & 5 & 113,40 & 9,53 & & \\
\hline Technology oriented ${ }^{*} 1^{\text {st }}$ year & 15 & 112,87 & 9,26 & \multirow{3}{*}{$F_{(2)}=0,420$} & \multirow{3}{*}{ NS } \\
\hline Technology oriented $3^{\text {rd }}$ year & 12 & 115,00 & 13,25 & & \\
\hline Technology oriented ${ }^{*} 6^{\text {th }}$ year & 10 & 116,50 & 4,95 & & \\
\hline Non-primary care ${ }^{*} 1^{\text {st }}$ year & 26 & 110,96 & 11,31 & \multirow{3}{*}{$F_{(2)}=2,104$} & \multirow{3}{*}{ NS } \\
\hline Non-primary care ${ }^{\star} 3^{\text {ra }}$ year & 28 & 113,04 & 12,37 & & \\
\hline Non-primary care ${ }^{*} 6^{\text {th }}$ year & 30 & 117,00 & 10,04 & & \\
\hline People oriented ${ }^{*} 1^{\text {st }}$ year & 22 & 114,27 & 11,27 & \multirow{3}{*}{$F_{(2)}=0,738$} & \multirow{3}{*}{ NS } \\
\hline People oriented ${ }^{*} 3^{\text {ra }}$ year & 16 & 114,44 & 8,54 & & \\
\hline People oriented ${ }^{*} 6^{\text {tn }}$ year & 20 & 118,15 & 13,24 & & \\
\hline
\end{tabular}

(a) $\mathrm{p}<0,05 ; \mathrm{NS}=$ Non-significant

No significant difference was found between the year in medical school and specialty groups: procedure, technology and peopleoriented. This study revealed no statistically significant effect on specialties and course year. The third year students reach higher scores in technology-oriented specialties but the best score of first and sixth year studentslies in people-oriented specialties.

\section{Discussion and conclusions}

The higher scores obtained by women are similar to other studies' results (Hojat et al., 2002; Magalhães et al., 2011) explained by the evolution of parental investment and maternal instinct. Females are therefore expected to develop a stronger sense of caring for offspring than men, which may highlight their ability to understand and 
communicate. The higher empathy levels among women could be based on a greater perception of emotions and their ability to be more open to emotional signals than men.

Similarly to the study by Hojat et al, 2002, 2005 , the results report higher empathy scores among students who were interested in people-oriented specialties (e.g. internal medicine, family medicine, pediatrics) rather than other specialties, although in the present study, it was not statistically significant. Hojat et al, (2005) state that the choice of peopleoriented specialties could be a reflection of students' personality and interpersonal orientation developed prior to medical school, or it could be a training result during medical education.

The choosing of the specialty may also be influenced by political issues of resource allocation and the regional needs of basic clinic care.

The present study shows that the Jefferson scale, when applied in different countries, is useful to observe the empathy scores among students but shows different global averages and some variations between countries.

Further research is needed to determine whether the participants actually revealed their feelings towards empathy or rather sought to show their desire to be helpful in order to fit into the profession. It is also essential to develop a longitudinal study to follow the first year students throughout their training in order to see if the teaching and learning process changes their perception of empathy.

\section{References:}

Chen, D., Lew, R., Hershman, W. \& Orlander, J. (2007) A Cross-sectional measurement of medical student empathy, Journal of General Internal Medicine, 22, 10, pp. 1434-1438.

Hojat, M., Gonnella, J., Mangione, S., Nasca, T., Veloski, J., Erdmann, J. \& Magee, M. (2002) The Jefferson Scale of Physician Empathy: Further psychometric data and differences by gender and specialty at item level, Academic Medicine, 77, pp.58-60.

Hojat, M., Zuckerman, M., Magee, M., Mangione, S., Nasca, T., Vergare, M. \& Gonnella, J. (2005) Empathy in medical students as related to specialty interest, personality and perceptions of mother and father, Personality and Individual Differences, 39, pp.1205-1215.

Hojat, M., Vergare, M., Maxwell, K., Brainard, G., Herrine, S., Isenberg, G., Veloski, J. \& Gonnella, $J$ (2009) The devil is in the third year: a longitudinal study of erosion of empathy in medical school, Academic Medicine, 84, 9, pp.1182-1191.

Kataoka, H., Norio Koide, N., Hojat, M. \& Gonnella, J. (2009) Measurement of empathy among Japanese medical students: Psychometrics and score differences by gender and level of medical education, Academic Medicine, 84, 9, pp.11921197.

Magalhães, E., DeChamplain, A., Salgueira, A., \& Costa, M.J (2010) Empatia Medica: Adaptação e validação de uma escala para estudantes de medicina, In Paper presented at the National Symposia of Psychology Research - Portugal. Edited by Nogueira, C., Silva, I., Lima, L., Almeida, AT., Cabecinhas, R., Gomes, R., Machado, C., Maia, A., Sampaio, A., \& Taveira, MC., 77-89 [http://www.actassnip2010.com].

Magalhães, E., Salgueira, AP., Costa, P. \& Costa, M.J (2011) Empathy in senior year and first year medical students: a cross-sectional study, BMC Medical Education, 11, p.52.

Pollak, K., Ostbye, T., Alexander, S., Gradison, M., Bastian, L., Brouwer, R., \& Lyna, P. (2007) Empathy goes a long way in weight loss discussions. Female patients are more likely to step up weight loss efforts when a physician shows empathy and offers support, The Journal of Family Practice, 56, 12, pp. 1031-1036.

Quince, T.A., Parker, R.A., Wood, D.F. \& Benson, J.A. (2011) Stability of empathy among undergraduate medical students: A longitudinal study at one UK medical school, BMC Medical Education, 11, p. 90.

Roh, M., Hahm, B., Lee, \& D., Suh, D (2010) Evaluation of empathy among Korean medical students: A cross-sectional study using the Korean Version of the Jefferson Scale of Physician Empathy, Teaching and Learning in Medicine, 22, 3, pp.167-171. 